\title{
Modeling road accident injury under-reporting in Europe
}

\author{
George Yannis • Eleonora Papadimitriou • \\ Antonis Chaziris • Jeremy Broughton
}

Received: 13 September 2013 / Accepted: 12 June 2014 / Published online: 26 June 2014

(C) The Author(s) 2014. This article is published with open access at SpringerLink.com

\begin{abstract}
Purpose In this research, a disaggregate analysis of road accident injury under-reporting in selected European countries is presented.

Method The level of injury under-reporting is expressed by under-reporting coefficients, estimated as the actual estimated number of road accident injuries of a given severity to the number of related injuries recorded by the Police. These coefficients were calculated within national/regional studies in the examined countries, through a specially developed uniform methodology of linking and matching Police road accident records and hospital records. Log-rate models are developed in order to estimate the combined effects of country (CZ, FR, GR, HU, NL, ES and the UK), road user type (car occupant, motorcyclist, pedal cyclist, pedestrian), Police severity score (serious or slight injury) and MAIS score (the maximum Abbreviated Injury Scale score) on under-reporting.

Results The results suggest that the examined characteristics have important combined effect on under-reporting (i.e. thirdorder interaction). The results of the analysis of lower-order interactions reveal specific particularities of each country/ region, indicating areas on which authorities should focus their efforts.

Conclusions For example, it was found that slight injuries are more likely to be under-reported than serious injuries in the Czech Republic, France, and Greece, while the opposite is the
\end{abstract}

G. Yannis $(\bowtie) \cdot$ E. Papadimitriou $\cdot$ A. Chaziris

Department of Transportation Planning and Engineering, National

Technical University of Athens, 5 Heroon Polytechniou St.,

15773 Athens, Greece

e-mail: geyannis@central.ntua.gr

J. Broughton

Transport Research Laboratory, Crowthorne House, Nine Mile Ride,

Wokingham, Berkshire RG40 3GA, United Kingdom case for the Netherlands and the UK. Moreover, although the Netherlands do not present high under-reporting rates overall, a particular issue is identified in this country for pedal cyclists' slight injuries. Finally, a considerable part of total underreporting in most countries can be attributed to injury severity mis-reporting.

Keywords Road accident injury $\cdot$ Under-reporting $\cdot$ Log-rate analysis $\cdot$ Injury severity

\section{Introduction}

In several EU Member States, significant discrepancies are observed between the non fatal road accident injury data provided by different data sources. The problem is known as road accident injury under-reporting, which is typically identified when comparing Hospital and Road Traffic Police data on road accident injuries and may be largely due to differences in injury severity definitions [14]. In particular, such comparisons reveal that only a limited proportion of non-fatal hospitalized injuries are recorded by the Police, while even less is known about the reporting of less severe (e.g. nonhospitalized) injuries. Several, mostly regional, studies provide evidence that an appreciable proportion of road accident injuries are not reported by the Police, whereas the level of under-reporting may differ among different levels of injury severity or different road user groups [12].

For example, a French regional study comparing Hospital with Road Traffic Police data found that only $37 \%$ of nonfatal hospitalized injuries were recorded by the Police [2]. In Australia, the use of a linked data system showed that about $40-45 \%$ of hospital records for road crash casualties did not have a corresponding police record [23]. A similar figure was estimated for child road accident injuries in Japan, through linkage of Police and Insurance Associations records [18]. 
Furthermore, a national under-reporting study in the UK [26], revealed a considerable difference of under-reporting among different levels of injury severity; about $20 \%$ of injuries classified as serious by the Police were treated and discharged by the hospital (i.e. slight injuries), while those treated by the hospital as serious but appearing in the police record as slight accounts for about $8 \%$ in that country.

Important differences in the degree of under-reporting per road user type were also identified in several studies. In San Fransisco, USA, the number of injured pedestrians is underreported by approximately $20 \%$ [24]. Moreover, Amoros et al. [1] found that Police under-reporting of road accident injuries in France is higher among the younger $(0-17)$ age and lower among the older (55+ years) age groups. Cryer et al. [7] estimated increased under-reporting of bicyclists and motorcyclists injuries in the UK.

The inclusion of an injury record in the Police file is mainly associated with the person's length of stay in hospital, the presence of physician in charge of the first aid, the type of accident area, the type of vehicles involved, the day and time of the accident and the blood alcohol concentration [2]. In New Zealand, injury under-reporting rates varied significantly by age, injury severity, month of crash, number of vehicles involved, and geographic region, but not by gender, ethnicity or day of the week of the crash [3].

In a meta-analysis of 49 studies in 13 countries, Elvik and Mysen [8] concluded that reporting of injuries in official accident statistics is incomplete at all levels of injury severity. In particular, the mean reporting level in the countries included was found to be $95 \%$ for fatal injuries according to the 30 day rule, $70 \%$ for serious injuries (defined as those admitted to hospital), $25 \%$ for slight injuries (defined as those treated as outpatients), and $10 \%$ for very slight injuries (defined as those treated outside hospitals). Moreover, injury reporting levels varied substantially among countries, ranging from 21 to $88 \%$ for hospital-treated injuries.

However, a number of studies underline that part of the under-reporting problem may be due to the fact that national accident statistics are generally compiled from information recorded by the police, yet police officers are not trained to record injury severity accurately. Zaloshnja and Miller [28] note that injury severity scores are assigned by police officers without medical training and typically without benefit of a hands-on examination. The ETSC [9] further suggests that assigning injury severity scores at an accident scene is impossible, since many life-threatening injuries cannot be observed at the scene and require clinical diagnosis in hospital.

Within this framework, under-reporting of non fatal injuries in national accident databases is an important limitation in European comparisons concerning non-fatal road accidents and related injuries, given that those databases are typically based on Police records. As far as fatal accidents and injuries are concerned, common
(European) definitions (i.e. fatalities within 30 days from the accident) exist and the low related level of under-reporting allows for meaningful comparisons to be carried out between most European countries. However, non fatal accidents and persons with non fatal injuries are not directly comparable at European level. In particular, the definitions of injury severity differ among countries, so that a casualty which would be recorded in one country might not be recorded in another country. Moreover, an injury which might be recorded as 'serious' in one country might be recorded as 'slight' in another country. Finally, the limited responsibility of the police in reporting injury severity properly, together with the randomness in the circumstances under which the reporting takes place (e.g. casualties taken from the scene before the police arrive) further complicates the comparability between countries.

The aim of the research is to analyse the differences in under-reporting rates amongst European countries and to identify the effect of related factors (e.g. road user type, injury severity) through log-rate models developed for this purpose. The level of road accident injury underreporting was quantified by means of appropriate underreporting coefficients for each European country/region, reflecting the rate of the estimated actual number of road accident casualties to the number of casualties recorded by the Police [5]. Eight studies were carried out on that purpose, using a specially developed uniform methodology, based on linking and matching Police and Hospital non fatal injury records. These studies, although with limited resources, resulting in some compromises about certain details of the methodology, aimed to approach a problem that had largely been ignored in the past, in a uniform and systematic way.

On the basis of the results of these studies, the present research compares the coefficients of non fatal injury underreporting among different countries/regions and analyzes their variation for different types of road users and different types of injuries. In order to model the variation in the under-reporting coefficients, an appropriate log-rate analysis technique was adopted. The log-rate analysis technique allows for examining both the magnitude and the statistical significance of single and combined effects of different factors on the underreporting coefficients.

The paper has the following structure: firstly, a short overview of the under-reporting coefficients is presented; secondly the methodology is described providing information on the statistical techniques applied. Thirdly, the log-rate modeling results are presented and statistically significant effects on under-reporting are compared in detail. Finally, a discussion of the results follows, highlighting the most important findings and their interpretation, the data limitations and the perspective for further research. 


\section{Data overview}

In this research, under-reporting coefficients were used to model the extent and variation of injury under-reporting in various areas in Europe. These coefficients were developed within the framework of the SafetyNet research project [5]. The basic approach adopted for the development of the coefficients is based on a linkage of road accident and medical databases, in order to identify an appropriate common European injury classification standard and identify the extent of under-reporting in national databases. It is noted that off-road crashes were not included in any of the national police accident reporting systems.

In order to calculate the under-reporting coefficients, medical records were cross-checked and matched with police road accident records. On the basis of a common methodology, national or regional studies were carried out in 8 European countries (Austria, Czech Republic, France, Greece, Hungary, The Netherlands, Spain and United Kingdom). Each study was carried out following a common framework of linking the road accident database (maintained usually by the police) to a medical database (from hospitals), to identify all common records and to copy details from the medical record of each linked casualty to the corresponding record in the police database. The combined police and medical data set of each study was used to produce a distinct threedimensional matrix of predefined common format for casualty counts, based on the severity of their injuries [6]. The characteristics of the studies, summarized in Table 1, varied as regards the sample size, the study area etc.; however the results of each study provide a good indication of the magnitude of road accident underreporting in the examined area [5].

As an example, the results of the linkage carried out within the UK study, which was a regional study covering the area of Scotland, are summarized in Table 2. It can be seen that, apart from the matching records, a number of extra casualties, not recorded by the Police, were found in the medical files. Moreover, a number of extra injuries, not recorded by Hospitals, were found in the Police files. For details on the matching and classification of injury records, the reader is referred to Broughton et al. [6] It is noted that external cause codes were used for identifying hospital-treated injury cases resulting from motor vehicle crashes on public roads, namely the International Classification of Diseases (ICD-9 for Spain and the Netherlands and ICD-10 for the other countries), from which the Abbreviated Injury Scale of each casualty can be calculated.

The under-reporting coefficients are calculated as the rate of the estimated actual number of road accident casualties divided by the number of casualties recorded by the police. The actual number of casualties is calculated as the sum of those recorded by the police plus the extra casualties identified in the hospital records [5]. Therefore, from the data of Table 2 it can be calculated that, in total, for each serious casualty in the police records (including the records not matched with hospitals) there are: $43610 /(17434+12 \quad 831)=1.44$ serious casualties in total, which corresponds to the classical definition of under-reporting, as the failure to record an injury.

The dissagregation of data by AIS (Abbreviated Injury Scale) score (maximum for each casualty - MAIS) allowed for the calculation of under-reporting with reference to specific actual AIS scores. The MAIS ranges from 1 to 6 , where a score equal to 1 suggests a slight injury, a score equal to 2 suggests a moderate injury, a score equal to 3 suggests a serious injury and so on, up to a score equal to 6 that suggests an untreatable injury.

For instance, it can also be calculated that for each serious casualty in the police records, there is actually (see Table 1):

$$
\begin{aligned}
& (5108+418+118+319) /(17434+12831) \\
& =0.20 \text { casualties with MAIS }(\text { Maximum AIS })>2 .
\end{aligned}
$$

Furthermore, a small proportion of casualties recorded as 'slight' by the police, actually had an MAIS $>2$ in the hospital records; this reflects a particular case of injury severity under-reporting, often referred as mis-reporting, where injury severity is underestimated by the police. In particular, there are:

$$
(670+61+2+31) /(8764+138334)
$$

$=0.005$ casualties with MAIS

$$
>2 \text { per slight casualty recorded by the police. }
$$

As it can be seen in Table 2, another proportion of casualties recorded as 'serious' by the police, actually had an MAIS equal to 1 or 2 , corresponding to another type of mis-reporting, that of overestimating injury severity [16].

It is noted that, within this research, the casualties found in the police records but not in hospital records were assumed to have an MAIS score equal to 1 or 2, corresponding thus to slight injuries that did not receive medical treatment.

Moreover, in each country, some minor road accidents may not be found in either the police or the hospitals' records, however the proportion and the severity of these accidents is expected to be negligible [5]. If a considerable proportion of 
Table 1 National/regional study characteristics

\begin{tabular}{lllc}
\hline Country & Study area & Period & Sample size \\
\hline Austria & National & 2001 & 69,233 \\
Czech Republic & Regional (Kromeriz, central Moravia) & $2003-2005$ & 1,649 \\
France & Regional (Département of Rhône) & $1996-2003$ & 90,457 \\
Greece & Regional (Island of Corfu) & $1996-2003$ & 11,915 \\
Hungary & Local (Part of Budapest) & Aug 2004-Jan 2006 & 3,459 \\
Netherlands & National & $1997-2003$ & 129,616 \\
Spain & Regional (Castilla y Leon) & July-December 2005 & 8,113 \\
UK & Regional (Scotland) & $1997-2005$ & 201,006 \\
\hline
\end{tabular}

such accidents had been suspected, the use of capturerecapture methods could have been implemented to estimate the number of casualties not recorded by any source $[4,17,25]$.

A uniform method was applied in all national studies for linking and matching Police and medical records, and the related overall under-reporting coefficients were calculated in all countries/regions according to the approach presented above; then, using a similar approach, the coefficients were disaggregated by road user type, Police severity score and MAIS score. The linkage of files underlying this research is probabilistic; therefore, uncertainty ranges are involved. In several cases (e.g. French and Greek studies), manual linkage was implemented for ambiguous records, in an attempt to minimise these uncertainty ranges. The estimated coefficients are presented in Table 3. It is noted that it has not been possible to calculate these coefficients from the Austrian national study, due to insufficient injury severity coding (only one ICD code per casualty) in the hospital records, not allowing to estimate the required MAIS scores.

\section{Methodology}

The objective of this modeling approach is to investigate whether the variation of injury under-reporting can be explained by country, road user type, police severity records or MAIS scores, and most importantly, by combinations of these parameters. More specifically, the analysis aims to associate under-reporting correction coefficients to a number of factors, including:

- Country/region effects, including the Czech Republic, France, Greece, Hungary, the Netherlands, Spain and the United Kingdom.

- Road user characteristics: car occupants, motorcyclists, pedal cyclists, pedestrians and other road users. It is noted that road user information was not available for Hungary and Spain. For these two countries, road user type values were replaced by the overall mean values for the different road user types across countries. Moreover, in Greece "other" also includes "unspecified" road users.

- Injury severity as recorded by the police, as "serious" or "slight".

- Maximum AIS scores: two groups were considered, including casualties with MAIS equal to 1 or 2 and casualties with MAIS $>2$.

- Combinations including two or more of the above parameters.

A log-rate modeling is considered to be most appropriate in the particular context, as under-reporting is measured by the related coefficients, which are rates of the estimated actual number of casualties to the number of casualties recorded by the Police. The log-rate model considered is a Poisson model, in which the actual number of casualties is the dependent variable and the number of casualties recorded by the Police is an offset term, allowing to model casualty rates rather than
Table 2 Police and hospital data linkage results - United Kingdom (Scotland)

\begin{tabular}{|c|c|c|c|c|c|c|c|c|}
\hline \multirow{2}{*}{$\begin{array}{l}\text { AIS of casualty } \\
\text { (Maximum) }\end{array}$} & \multicolumn{2}{|c|}{ Linked cases } & \multicolumn{2}{|c|}{ Extras in hospitals } & \multicolumn{2}{|c|}{ Extras in police } & \multicolumn{2}{|c|}{ Estimated total } \\
\hline & Serious & Slight & Serious & Slight & Serious & Slight & Serious & Slight \\
\hline 1 or 2 & 13,797 & 8,299 & 11,019 & 7,028 & 12,831 & 138,334 & 37,647 & 153,661 \\
\hline 3 & 3,139 & 412 & 1.969 & 258 & 0 & 0 & 5.108 & 670 \\
\hline 4 & 226 & 33 & 192 & 28 & 0 & 0 & 418 & 61 \\
\hline 5 & 75 & 1 & 43 & 1 & 0 & 0 & 118 & 2 \\
\hline 6 & 197 & 19 & 122 & 12 & 0 & 0 & 319 & 31 \\
\hline all & 17,434 & 8,764 & 13,345 & 7,327 & & & 43,610 & 154,425 \\
\hline
\end{tabular}


Table 3 Under-reporting correction coefficients (source: [6])

\begin{tabular}{|c|c|c|c|c|c|c|c|c|c|c|c|c|c|}
\hline \multirow[b]{2}{*}{ Country } & \multirow[b]{2}{*}{ MAIS } & \multicolumn{2}{|c|}{ Car occupant } & \multicolumn{2}{|c|}{ Motorcyclist } & \multicolumn{2}{|c|}{ Pedal cyclist } & \multicolumn{2}{|c|}{ Pedestrian } & \multicolumn{2}{|l|}{ Other } & \multicolumn{2}{|l|}{ All } \\
\hline & & Serious & Slight & Serious & Slight & Serious & Slight & Serious & Slight & Serious & Slight & Serious & Slight \\
\hline \multirow[t]{3}{*}{ Czech Republic } & 1 or 2 & 0.97 & 1.11 & 1.03 & 1.17 & 1.11 & 3.50 & 1.05 & 1.77 & 0.88 & 1.00 & 1.07 & 1.56 \\
\hline & $>2$ & 0.11 & 0.01 & 0.09 & 0.01 & 0.50 & 0.04 & 0.35 & 0.04 & 0.13 & 0.00 & 0.21 & 0.02 \\
\hline & All & 1.08 & 1.12 & 1.12 & 1.18 & 1.61 & 3.54 & 1.40 & 1.80 & 1.00 & 1.00 & 1.28 & 1.58 \\
\hline \multirow[t]{3}{*}{ France } & 1 or 2 & 1.32 & 2.38 & 1.35 & 3.13 & 4.69 & 10.39 & 1.01 & 1.90 & 1.52 & 2.67 & 1.43 & 2.69 \\
\hline & $>2$ & 0.51 & 0.03 & 0.83 & 0.12 & 1.97 & 0.27 & 0.57 & 0.10 & 1.06 & 0.06 & 0.68 & 0.06 \\
\hline & All & 1.84 & 2.41 & 2.18 & 3.25 & 6.67 & 10.66 & 1.58 & 2.00 & 2.58 & 2.73 & 2.11 & 2.75 \\
\hline \multirow[t]{3}{*}{ Greece } & 1 or 2 & 4.62 & 6.40 & 3.19 & 4.42 & 8.33 & 20.58 & 2.49 & 3.91 & 11.82 & 15.17 & 4.54 & 6.39 \\
\hline & $>2$ & 0.53 & 0.13 & 0.27 & 0.09 & 0.17 & 1.17 & 0.45 & 0.14 & 0.69 & 0.09 & 0.46 & 0.12 \\
\hline & All & 5.14 & 6.53 & 3.46 & 4.50 & 8.50 & 21.75 & 2.93 & 4.04 & 12.51 & 15.26 & 5.00 & 6.51 \\
\hline \multirow[t]{3}{*}{ Netherlands } & 1 or 2 & 1.07 & 1.02 & 1.21 & 1.04 & 1.90 & 1.10 & 1.23 & 1.04 & 1.24 & 1.01 & 1.29 & 1.04 \\
\hline & $>2$ & 0.22 & 0.01 & 0.37 & 0.02 & 0.73 & 0.04 & 0.36 & 0.02 & 0.21 & 0.01 & 0.39 & 0.02 \\
\hline & All & 1.29 & 1.02 & 1.59 & 1.05 & 2.63 & 1.14 & 1.59 & 1.06 & 1.45 & 1.02 & 1.68 & 1.05 \\
\hline \multirow[t]{3}{*}{ UK } & 1 or 2 & 1.15 & 1.03 & 1.34 & 1.13 & 2.54 & 1.24 & 1.05 & 1.03 & 1.62 & 1.06 & 1.24 & 1.04 \\
\hline & $>2$ & 0.15 & 0.00 & 0.27 & 0.01 & 0.29 & 0.01 & 0.23 & 0.01 & 0.26 & 0.01 & 0.20 & 0.01 \\
\hline & All & 1.30 & 1.03 & 1.61 & 1.14 & 2.83 & 1.25 & 1.28 & 1.04 & 1.88 & 1.07 & 1.44 & 1.05 \\
\hline \multirow[t]{3}{*}{ Hungary } & 1 or 2 & & & & & & & & & & & 0.84 & 1.27 \\
\hline & $>2$ & & & & & & & & & & & 0.48 & 0.04 \\
\hline & All & & & & & & & & & & & 1.32 & 1.31 \\
\hline \multirow[t]{3}{*}{ Spain } & 1 or 2 & & & & & & & & & & & 1.22 & 1.06 \\
\hline & $>2$ & & & & & & & & & & & 0.26 & 0.02 \\
\hline & All & & & & & & & & & & & 1.48 & 1.07 \\
\hline
\end{tabular}

counts. Moreover, all four explanatory variables in this model are categorical, and therefore the rates can be disaggregated up to a four-dimensional Table, so that the Poisson model includes all main effects and interactions between those categorical variables.

A four-dimensional Table of $\mathrm{i}$ rows, $\mathrm{j}$ columns and $\mathrm{k}, \mathrm{l}$ layers can then be decomposed in row effects, column effects, layer effects and their interactions, including first order interactions (e.g. ixj, ixk, and so on), second order interactions (e.g. ixjxl, ixkxl, and so on) and the third order interaction (ixjxkxl). The log-rate analysis uses an additive model that incorporates main effects and interactions between variables (for example 1: country, 2: road user type, 3: police severity, 4: MAIS score) in the following form:

$$
\begin{aligned}
\operatorname{LogN} *_{\mathrm{ijkl}}= & \log _{\mathrm{ijkl}}+\mathrm{u}+\mathrm{u}_{1(\mathrm{i})}+\mathrm{u}_{2(\mathrm{j})}+\mathrm{u}_{3(\mathrm{k})}+\mathrm{u}_{4(\mathrm{l})}+\mathrm{u}_{12(\mathrm{ij})}+\mathrm{u}_{13(\mathrm{ik})}+\mathrm{u}_{14(\mathrm{il})}+\mathrm{u}_{23(\mathrm{jk})} \\
& +\mathrm{u}_{24(\mathrm{jl})}+\mathrm{u}_{34(\mathrm{kl})}+\mathrm{u}_{123(\mathrm{ijk})}+\mathrm{u}_{124(\mathrm{ijl})}+\mathrm{u}_{134(\mathrm{ikl})}+\mathrm{u}_{234(\mathrm{jkl})}+\mathrm{u}_{1234(\mathrm{ijk})}
\end{aligned}
$$

Where $\mathrm{N}^{*}{ }_{\mathrm{ijk} l}$ are the expected cell frequencies, $\mathrm{N}_{\mathrm{ijkl}}$ is an offset term and $\mathrm{u}$ are parameters to be estimated. In this case, the under-reporting coefficients are modeled as the rate of the actual number of casualties $\mathrm{N}^{*}{ }_{\mathrm{ijk} 1}$ to the number of casualties recorded by the police $\mathrm{N}^{*}{ }_{\mathrm{ijk} k}$. The above formula for a fourdimensional Table corresponds to a saturated log-rate model, containing all possible third- and lower-order effects. Moreover, it should be underlined that the models considered are hierarchical, meaning that whenever a higher order effect is included in the model, the lower order effects composed from variables in the higher effect are also included [10, 15].

In the framework of the present study, the third-order interaction (i.e. interaction of four variables) is particularly interesting since, if this effect is significant, then there is a significant interaction of all the examined parameters with respect to injury under-reporting. If (and only if) not, then the various lower order effects can be further analysed and interpreted [11]. For example, if the interaction of country and 
road user type is found to be significant, this would mean that injury under-reporting is not only significantly different between countries, but that the way countries differ varies between user groups.

The hypotheses of the analysis are those of mutual independence, which specifies that there are no associations of any kind between the four variables, or in other words that there are no first-order interactions between any pair of variables and no conjoint three or four-variable interaction. Main effect parameters are measured as deviations of row, column or layer means of log-rates from the overall mean. Each of the $u$ parameters represents a deviation from the grand mean due to that effect [13]. From the best-fitting log-rate model, the parameter estimates and their statistical significance are determined. The ultimate test is whether the table generated by the model closely fits the observed table. A likelihood ratio goodness-of-fit statistic is used to accept or reject the model [10].

It is underlined, though, that the presence of a third-order interaction does not allow for the analysis of lower-order effects in the full model, given that these lower-order effects should not be interpreted as aggregate variable effects, but rather as contributions of particular effects to the magnitude of the third-order interaction, an issue that is often overlooked in related analyses. Consequently, in order to investigate lowerorder effects in the presence of a higher-order interaction, it is recommended to fit the appropriate models corresponding to more aggregate forms of the data. For example, if the interaction of country, road user type and MAIS is found to be significant in a log-rate analysis of a three-dimensional Table describing the data, the parameter estimates of the model for countries can not be interpreted as country effects, but as contributions of the country effect to the second-order interaction. In order to analyze country effects in this case, a separate log-rate analysis of under-reporting rates per country alone should be carried out.

\section{Results}

In this section, the results from the log-rate analysis of the under-reporting coefficients are presented together with an interpretation of the modeling results. Initially, the full disaggregation of the data in a four-dimensional Table is examined. Then, more aggregate analyses of the data are presented, in order to provide an overall picture on the effects of the four variables and their basic combinations. In any case, it is noted that a dummy coding is used, in which all parameter estimates for each variable are estimated in relation to a value of reference, taken typically as the last category of each variable (reference categories are mentioned in the legends of Tables and Figures). Moreover, the parameter estimates of the log-rate models are in fact log-odds ratios, and can be therefore interpreted accordingly.

\subsection{Analysis of highest-order effects}

The identification of the highest potential generating class for the model (i.e. the highest order significant interaction between variables) was the first step of the present analysis. The third-order interaction was significant, suggesting that there is a significant joint association of all the examined variables (country, road user type, MAIS score and police severity) with respect to under-reporting. This means that differences in under-reporting do exist at the most disaggregate level of the parameters examined, for instance under-reporting of pedal cyclists' injuries recorded by the Police as slight and having an MAIS score 1 or 2 in the Netherlands is significantly different from the under-reporting of other road users injuries recorded as serious by the Police and having an MAIS score higher than 2 in the UK (Scotland).

According to the above, a saturated model's design was generated for the log-rate model i.e. a design including all possible single and combined effects (interactions), resulting with a model having as generating class the interaction [country*road user type* police severity*MAIS score].

The modelling results of the saturated model are presented in Table 4. It is reminded that, the effects concerning road user groups for the Hungarian and Spanish regions were not available and were therefore considered to be equal to the overall mean (for all road users) for these regions, consequently the results concern only the five other countries/regions.

In this case, given the presence and significance of the third-order interaction, the analysis of lower effects by this model is not meaningful. Consequently, only third-order effects (i.e. four variables interactions) are discussed here. The odds-ratios indicate the relative odds of underreporting casualties with a combination of characteristics, to under-reporting casualties with the reference groups' characteristics. Generally, an odds ratio higher than 1 suggests increased probability of under-reporting compared to the reference group, whereas an odds ratio lower than 1 suggests lower probability of under-reporting compared to the reference group. For example, in Table 4, pedestrian injuries that are considered slight by both police and hospitals (MAIS 1 or 2) are less under-reported in the French region (odds ratio equals 0.70 ) compared to other road users' serious injuries in the Greek region (reference group), and more under-reported in Scotland (odds ratio equals 1.98), compared to other road users' serious injuries in the Greek region.

Moreover, the results of Table 4 suggest that underreporting of pedal cyclists' casualties with MAIS 1 or 2 recorded as slight by the police is 25 times more likely in the Czech region and 10 times more likely in Scotland, 
Table 4 Statistically significant parameter estimates of the full model (with third-order interaction)

\begin{tabular}{|c|c|c|c|c|}
\hline Parameter & Estimate B & Std. Error & $p$-value & $\operatorname{Exp}(B)$ \\
\hline Constant & -0.368 & 0.030 & 0.000 & 0.692 \\
\hline [Czech Republic] & -1.634 & 0.274 & 0.000 & 0.195 \\
\hline [France $]$ & 0.426 & 0.031 & 0.000 & 1.531 \\
\hline [Netherlands] & -1.175 & 0.032 & 0.000 & 0.309 \\
\hline$[\mathrm{UK}]$ & -0.984 & 0.031 & 0.000 & 0.374 \\
\hline [MAIS 1 or 2 ] & 2.806 & 0.030 & 0.000 & 16.550 \\
\hline$[\mathrm{Car}]$ & -0.186 & 0.038 & 0.000 & 0.830 \\
\hline [Pedal cycle] & -1.256 & 0.393 & 0.001 & 0.285 \\
\hline [Pedestrian] & -0.434 & 0.043 & 0.000 & 0.648 \\
\hline [Slight injury] & -2.051 & 0.108 & 0.000 & 0.129 \\
\hline [Czech Republic] * [MAIS 1 or 2] & -0.936 & 0.277 & 0.001 & 0.392 \\
\hline$[$ France $] *[$ MAIS 1 or 2$]$ & -2.448 & 0.032 & 0.000 & 0.086 \\
\hline [Netherlands] * [MAIS 1 or 2] & -1.050 & 0.032 & 0.000 & 0.350 \\
\hline$[\mathrm{UK}] *[$ MAIS 1 or 2$]$ & -0.972 & 0.031 & 0.000 & 0.378 \\
\hline [Czech Republic] $*$ [motorcycle] & -0.365 & 0.359 & 0.310 & 0.694 \\
\hline [Czech Republic] * [pedal cycle] & 2.566 & 0.480 & 0.000 & 13.018 \\
\hline [Czech Republic] $*$ [pedestrian] & 1.389 & 0.281 & 0.000 & 4.009 \\
\hline$[$ France $] *[$ car $]$ & -0.541 & 0.040 & 0.000 & 0.582 \\
\hline$[$ France $] *$ [motorcycle $]$ & -0.232 & 0.034 & 0.000 & 0.793 \\
\hline [France] $*$ [pedal cycle] & 1.878 & 0.393 & 0.000 & 6.540 \\
\hline [France] $*$ [pedestrian] & -0.190 & 0.044 & 0.000 & 0.827 \\
\hline [Netherlands] $*$ [car $]$ & 0.198 & 0.041 & 0.000 & 1.219 \\
\hline [Netherlands] $*$ [motorcycle] & 0.575 & 0.035 & 0.000 & 1.777 \\
\hline [Netherlands] $*$ [pedal cycle] & 2.480 & 0.394 & 0.000 & 11.945 \\
\hline [Netherlands] $*$ [pedestrian] & 0.956 & 0.045 & 0.000 & 2.601 \\
\hline$[\mathrm{UK}] *[\mathrm{car}]$ & -0.362 & 0.040 & 0.000 & 0.696 \\
\hline$[\mathrm{UK}] *$ [pedal cycle $]$ & 1.368 & 0.394 & 0.001 & 3.927 \\
\hline$[\mathrm{UK}] *$ [pedestrian] & 0.303 & 0.044 & 0.000 & 1.353 \\
\hline [Czech Republic] * [slight injury] & -1.262 & 0.356 & 0.000 & 0.283 \\
\hline [France ${ }^{*}[$ slight injury $]$ & -0.853 & 0.119 & 0.000 & 0.426 \\
\hline [Netherlands] $*$ [slight injury] & -1.346 & 0.246 & 0.000 & 0.260 \\
\hline$[\mathrm{UK}] *$ [slight injury $]$ & -1.714 & 0.176 & 0.000 & 0.180 \\
\hline [MAIS 1 or 2] $*$ [car] & -0.847 & 0.039 & 0.000 & 0.429 \\
\hline [MAIS 1 or 2] $*$ [motorcycle] & -0.495 & 0.032 & 0.000 & 0.610 \\
\hline [MAIS 1 or 2$] *$ [pedal cycle] & 0.833 & 0.393 & 0.034 & 2.301 \\
\hline [MAIS 1 or 2] * [slight injury] & 2.348 & 0.108 & 0.000 & 10.468 \\
\hline$[\mathrm{Car}] *[$ slight injury $]$ & 0.810 & 0.117 & 0.000 & 2.247 \\
\hline [Motorcycle] $*$ [slight injury] & 0.791 & 0.111 & 0.000 & 2.206 \\
\hline [Pedal cycle $] *$ [slight injury $]$ & 3.830 & 0.409 & 0.000 & 46.046 \\
\hline$[$ Pedestrian $] *[$ slight injury $]$ & 0.875 & 0.125 & 0.000 & 2.398 \\
\hline [Czech Republic] $*$ [MAIS 1 or 2] $*$ [car] & 1.142 & 0.295 & 0.000 & 3.134 \\
\hline [Czech Republic] $*$ [MAIS 1 or 2] * [motorcycle] & 1.032 & 0.362 & 0.004 & 2.807 \\
\hline [Czech Republic] $*$ [MAIS 1 or 2$] *$ [pedal cycle] & -1.904 & 0.482 & 0.000 & 0.149 \\
\hline$[$ France $] *[$ MAIS 1 or 2$] *[$ car $]$ & 1.438 & 0.041 & 0.000 & 4.211 \\
\hline$[$ France $] *[$ MAIS 1 or 2$] *$ [motorcycle $]$ & 0.622 & 0.034 & 0.000 & 1.863 \\
\hline$[$ France $] *[$ MAIS 1 or 2$] *$ pedestrian $]$ & 1.310 & 0.045 & 0.000 & 3.706 \\
\hline [Netherlands] $*[$ MAIS 1 or 2$] *[\mathrm{car}]$ & 0.693 & 0.041 & 0.000 & 2.000 \\
\hline$[$ Netherlands $] *[$ MAIS 1 or 2$] *$ [motorcycle $]$ & -0.089 & 0.035 & 0.010 & 0.915 \\
\hline [Netherlands] $*$ [MAIS 1 or 2$] *$ [pedal cycle $]$ & -1.628 & 0.394 & 0.000 & 0.196 \\
\hline
\end{tabular}


Table 4 (continued)

\begin{tabular}{|c|c|c|c|c|}
\hline Parameter & Estimate B & Std. Error & $p$-value & $\operatorname{Exp}(B)$ \\
\hline$[$ Netherlands] $*$ [MAIS 1 or 2] $*$ [pedestrian] & 0.563 & 0.045 & 0.000 & 1.755 \\
\hline$[\mathrm{UK}] *[$ MAIS 1 or 2$] *[\mathrm{car}]$ & 1.050 & 0.040 & 0.000 & 2.857 \\
\hline$[\mathrm{UK}] *[$ MAIS 1 or 2$] *$ [motorcycle] & 0.270 & 0.034 & 0.000 & 1.311 \\
\hline$[\mathrm{UK}] *[$ MAIS 1 or 2$] *[$ pedestrian $]$ & 0.793 & 0.044 & 0.000 & 2.210 \\
\hline [Czech Republic] * [MAIS 1 or 2] * [slight injury] & 1.098 & 0.354 & 0.002 & 2.997 \\
\hline$[$ France $] *[$ MAIS 1 or 2$] *$ [slight injury $]$ & 1.123 & 0.120 & 0.000 & 3.074 \\
\hline [Netherlands] $*$ [MAIS 1 or 2$] *$ [slight injury] & 0.851 & 0.246 & 0.001 & 2.342 \\
\hline$[\mathrm{UK}] *[$ MAIS 1 or 2$] *$ [slight injury $]$ & 0.994 & 0.176 & 0.000 & 2.702 \\
\hline [Czech Republic] ${ }^{*}$ [pedal cycle] $*$ [slight injury] & -3.063 & 0.571 & 0.000 & 0.047 \\
\hline$[\text { Czech Republic }]^{*}[$ pedestrian $] *$ [slight injury $]$ & 0.234 & 0.047 & 0.000 & 1.264 \\
\hline$[$ France $] *[$ car $] *[$ slight injury $]$ & -0.771 & 0.130 & 0.000 & 0.463 \\
\hline$[$ France $] *[$ pedal cycle $] *[$ slight injury $]$ & -2.896 & 0.412 & 0.000 & 0.055 \\
\hline$[$ France $] *[$ pedestrian $] *[$ slight injury $]$ & 0.268 & 0.136 & 0.049 & 1.308 \\
\hline$[$ Netherlands $] *[$ car $] *[$ slight injury $]$ & -0.925 & 0.255 & 0.000 & 0.396 \\
\hline$[$ Netherlands $] *$ [motorcycle $] *$ [slight injury $]$ & -0.521 & 0.249 & 0.036 & 0.594 \\
\hline$[$ Netherlands $] *$ [pedal cycle] $*$ [slight injury $]$ & -3.308 & 0.465 & 0.000 & 0.037 \\
\hline$[\mathrm{UK}] *[\mathrm{car}] *[$ slight injury $]$ & -0.688 & 0.199 & 0.001 & 0.502 \\
\hline$[\mathrm{UK}] *[$ pedal cycle $] *[$ slight injury $]$ & -3.532 & 0.452 & 0.000 & 0.029 \\
\hline$[\mathrm{UK}] *[$ pedestrian $] *[$ slight injury $]$ & -0.434 & 0.204 & 0.033 & 0.648 \\
\hline [MAIS 1 or 2$] *$ [car] $*$ [slight injury] & -0.706 & 0.117 & 0.000 & 0.494 \\
\hline [MAIS 1 or 2$] *[$ motorcycle $] *$ [slight injury $]$ & -0.646 & 0.111 & 0.000 & 0.524 \\
\hline [MAIS 1 or 2$] *$ [pedal cycle] $*$ [slight injury] & -2.974 & 0.409 & 0.000 & 0.051 \\
\hline [MAIS 1 or 2$] *$ [pedestrian] $*$ [slight injury] & -0.720 & 0.125 & 0.000 & 0.487 \\
\hline [Czech Republic] * [MAIS 1 or 2] * [pedal cycle] * [slight injury] & 3.221 & 0.570 & 0.000 & 25.047 \\
\hline$[$ France $] *[$ MAIS 1 or 2$] *[$ car $] *$ [slight injury $]$ & 0.687 & 0.130 & 0.000 & 1.988 \\
\hline [France] $*$ [MAIS 1 or 2] * [pedal cycle] $*$ [slight injury] & 2.267 & 0.413 & 0.000 & 9.654 \\
\hline$[$ France $] *[$ MAIS 1 or 2$] *$ [pedestrian $] *$ [slight injury $]$ & -0.357 & 0.137 & 0.009 & 0.700 \\
\hline [Netherlands] $*$ [MAIS 1 or 2] $*$ [car] $*$ [slight injury] & 0.965 & 0.255 & 0.000 & 2.626 \\
\hline$[$ Netherlands $] *[$ MAIS 1 or 2$] *$ [pedal cycle $] *$ [slight injury $]$ & 2.099 & 0.465 & 0.000 & 8.161 \\
\hline$[\mathrm{UK}] *[$ MAIS 1 or 2$] *[$ car $] *[$ slight injury $]$ & 0.898 & 0.199 & 0.000 & 2.455 \\
\hline$[\mathrm{UK}] *[$ MAIS 1 or 2$] *$ [pedal cycle] $*$ [slight injury $]$ & 2.381 & 0.452 & 0.000 & 10.817 \\
\hline [UK] $*$ [MAIS 1 or 2$] *$ [pedestrian] $*$ [slight injury] & 0.682 & 0.204 & 0.001 & 1.977 \\
\hline
\end{tabular}

Reference groups: Country: Greece, Police severity: serious, MAIS > 2, Road user type: other road user

compared to under-reporting of other road users' casualties with MAIS $>2$ recorded as serious by the Police in the Greek region (reference groups). The validity of these odds ratios is indicated by the statistical significance of the parameter estimates of the model.

The results show that most of the estimated odds-ratios are higher than one, suggesting that slight casualties tend to be more under-reported than serious ones (taken as the reference group here), which is intuitive. Overall by far the highest odds-ratios of injury under-reporting are associated with slight injuries of pedal cyclists in the Czech Republic region, the Netherlands, the French region and the Greek region. It is deduced that pedal cyclists' casualties that are recorded as slight both according to the Police and the hospitals' classification are most likely to be under-reported in these areas. Increased odds of under-reporting are also observed with respect to slight injuries of car occupants in the French region, the Greek region and the Netherlands. On the other hand, slight pedestrian's injuries in the French region present the lowest odds of under-reporting compared to all countries/ regions, injury types and road user types.

Obviously, comparisons at such a disaggregate level are not appropriate for the understanding of the overall effects of factors determining the under-reporting problem in each area or across areas. However the important information obtained by these results is that even the most detailed combinations of casualty type may present significant differences between them in terms of under-reporting. Therefore, all examined 
variables have important combined explanatory effects on the level of under-reporting in Europe, which could not be fully explained by a more parsimonious model. In order to explore particular variables' effects, one has to examine less disaggregate forms of the data, by fitting separate lower-order submodels. The most important findings of these analyses are presented in the next section.

\subsection{Analysis of lower-order effects}

Additional log-rate analyses were carried out for the estimation of overall under-reporting rates between countries/ regions, which are presented in Table 5. These results suggest that injury under-reporting is generally higher in the Greek region (around three times higher than the other areas), and also slightly higher in the French, Spanish and Hungarian regions, compared to the other areas, a finding that may be partly reflecting the degree to which outpatients are included in the hospital records (i.e. the estimated actual number of casualties is expected to be higher in areas whose hospital records include outpatients).

A similar picture is obtained by the log-rate analysis of the combined effect of country and police or hospital recorded injury severity, also presented in Table 5, suggesting that, in general, the national/regional degree of under-reporting is largely determined by the under-reporting of slight casualties (see Fig. 1). Nevertheless, it can be seen that slight injuries are more likely to be under-reported than serious injuries in the Czech Republic, French, Greek and Hungarian regions, compared to the Spanish region. The opposite is the case for the Netherlands and the UK, where slight injuries are less likely to be under-reported than serious injuries, compared to the Spanish region. On the other hand, all countries present significantly lower relative odds of under-reporting casualties classified by hospitals with MAIS 1 or 2, and only the Greek region presents increased odds of under-reporting these casualties, compared to Spain.

On the basis of these results, the overall under-reporting in the Greek region may be attributed to the increased odds of under-reporting casualties that are classified as slight both by the police and by the hospitals (MAIS 1 or 2), while in the French, Hungarian and the Czech regions the overall underreporting may be attributed to the increased odds of under-reporting casualties that are classified as slight by the Police and casualties that are assigned an MAIS $>2$ by the hospitals. In the latter case, it appears that the overall under-reporting rates of these areas are significantly affected by injury mis-reporting by the police.

Table 5 Parameter estimates of log-rate sub-models of country/region and injury severity effects on under-reporting

\begin{tabular}{|c|c|c|c|c|}
\hline Parameter & Estimate & Std. error & $p$-value & $\operatorname{Exp}(B)$ \\
\hline \multicolumn{5}{|l|}{ [Country] } \\
\hline [Czech Republic] & -0.392 & 0.002 & $0.000 *$ & 0.676 \\
\hline [France] & 0.291 & 0.001 & $0.000 *$ & 1.338 \\
\hline [The Netherlands] & -0.319 & 0.001 & $0.000 *$ & 0.727 \\
\hline$[\mathrm{UK}]$ & -0.904 & 0.001 & $0.000 *$ & 0.405 \\
\hline [Greece] & 1.168 & 0.001 & $0.000 *$ & 3.216 \\
\hline [Hungary] & -0.046 & 0.001 & $0.000 *$ & 0.955 \\
\hline \multicolumn{5}{|l|}{ [Country*Mais] } \\
\hline [Czech Republic] $*$ [MAIS: 1 or 2] & -0.94 & 0.029 & $0.000 *$ & 0.910 \\
\hline$[$ France $] *[$ MAIS: 1 or 2$]$ & -0.755 & 0.005 & $0.000 *$ & 0.470 \\
\hline [the Netherlands] * [MAIS: 1 or 2] & -0.420 & 0.004 & $0.000 *$ & 0.657 \\
\hline$[\mathrm{UK}] *[$ MAIS: 1 or 2$]$ & -0.419 & 0.005 & $0.000 *$ & 0.658 \\
\hline [Greece] $*$ [MAIS: 1 or 2$]$ & 0.753 & 0.010 & $0.000 *$ & 2.214 \\
\hline [Hungary $]^{*}[$ MAIS: 1 or 2$]$ & -0.792 & 0.006 & $0.000 *$ & 0.453 \\
\hline \multicolumn{5}{|l|}{ [Country*Police severity] } \\
\hline [Czech Republic] * [Police: slight] & 0.610 & 0.008 & $0.000 *$ & 1.840 \\
\hline$[$ France $] *[$ Police: slight $]$ & 0.413 & 0.001 & $0.000 *$ & 1.511 \\
\hline [the Netherlands] $*$ [Police: slight] & -0.282 & 0.001 & $0.000 *$ & 0.754 \\
\hline$[\mathrm{UK}] *[$ Police: slight $]$ & -0.540 & 0.001 & $0.000 *$ & 0.583 \\
\hline [Greece ${ }^{*}[$ Police: slight $]$ & 0.626 & 0.001 & $0.000 *$ & 1.869 \\
\hline [Hungary $] *[$ Police: slight $]$ & 0.226 & 0.003 & $0.000 *$ & 1.254 \\
\hline
\end{tabular}

Reference groups: Country: Spain, Police severity: Serious injury, MAIS $>2$

* indicates a significant effect 

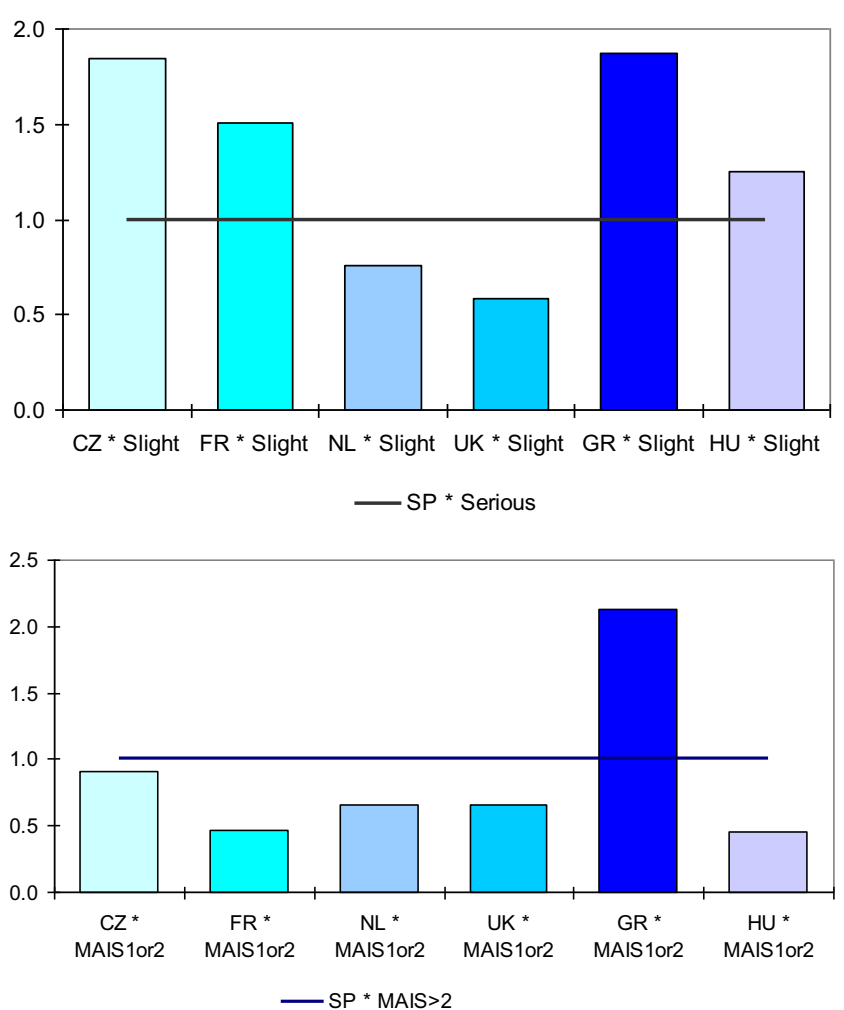

Fig. 1 Relative underreporting rates between countries/regions and police-recorded severity (top) and MAIS (bottom)

Consequently, the important role of the extent to which police misreports injury severity is confirmed.

Other significant results are those concerning underreporting per country/regions and road user type; these are presented in Table 6 and demonstrated in Fig. 2. In particular, the odds of under-reporting pedestrian casualties are relatively high compared with other road users in all areas, compared to the Greek region. Moreover, pedal cyclists' injury underreporting is increased in the Czech and French regions. These results are largely due to the fact that, although absolute underreporting rates are increased for all road users' injuries in the Greek region compared to other areas, under-reporting of 'other' road users' casualties is by far the highest in the Greek region. This reveals insufficient recording of the information related to road user type in that Greek region and results in very low odds of under-reporting cars, motorcyclists', pedal cyclists' and pedestrians' casualties in that particular area.

Proceeding to second order effects, the most significant differences are those associating under-reporting to country/ region, road user type and police severity score, presented in Fig. 3, which is an extension of Fig. 2 with one more variable (reference groups 'Greece', 'other' road users and police severity: serious). The odds of under-reporting police recorded slight injuries compared to serious injuries are generally lower for all areas compared to the Greek region. Police recorded slight injuries of car occupants, motorcyclists and pedestrians are more likely to be under-reported in the French region and in the UK region compared to the Greek region, which confirms the increased under-reporting of 'other' road users' injuries in the Greek region.

Moreover, police recorded slight injuries of pedal cyclists are less likely to be under-reported in all areas compared to the Greek region. Given that the third-order interaction (see previous section) suggests that pedal cyclists' injuries that are recorded as slight by both hospitals and police have increased odds of being under-reported, it can be deduced that it is the injuries recorded as slight by the police but assigned an MAIS $>2$ by hospitals that are less likely to be underreported in all countries/regions compared to the Greek region.

\section{Discussion}

The present study developed accident injury under-reporting models for several European countries/regions, an important research topic which has not been adequately explored so far. The analysis exploited existing under-reporting coefficients [6] in order to investigate the magnitude and the variation of under-reporting in Europe at a disaggregate level.

These under-reporting coefficients were developed through a uniform methodology applied for the first time in different areas in order to estimate the actual number of road accident casualties in a number of pilot countries/regions and to identify an appropriate methodology for future studies. Although the results may not always allow for straightforward comparisons to be made due to the complexity and particularities of each national/regional study, the development of a log-rate model provided useful and analytical results concerning the variation of under-reporting in several European areas by several variables. More specifically, it was confirmed that country/region, road user and injury type characteristics have important combined effects on under-reporting. Therefore, different combinations of these characteristics results in significantly different degrees of under-reporting in different areas. Special emphasis was also given to the fact that lower-order effects should not be interpreted in the presence of higher-order effects in the same model.

The results of the full disaggregate data set in a saturated log-rate model reveal that the odds of road accident injury under-reporting is almost 10 times higher as regards injuries of pedal cyclists which are classified as slight by both police and hospitals in the Czech, French, UK regions and in the Netherlands, compared to the Greek regions. It is important to note that UK (Scotland) and the Netherlands present the lowest average under-reporting levels.

More aggregate log-rate analyses were also carried out, in order to investigate the aggregate effects of specific variables. Injury under-reporting is generally more likely in the Greek, 
Table 6 Parameter estimates of log-rate sub-models of country/region, road user type and injury severity effects on under-reporting

\begin{tabular}{|c|c|c|c|c|}
\hline Parameter & Estimate B & Std. Error & $p$-value & $\operatorname{Exp}(B)$ \\
\hline \multicolumn{5}{|l|}{ [Country]*[Road user type] } \\
\hline [Czech Republic] * [car & 1.045 & 0.014 & $0.000 *$ & 2.844 \\
\hline [Czech Republic] * [motorcycle] & 0.690 & 0.016 & $0.000 *$ & 1.993 \\
\hline [Czech Republic] * [pedal cycle] & 0.741 & 0.014 & $0.000 *$ & 2.097 \\
\hline [Czech Republic] * [pedestrian] & 1.979 & 0.015 & $0.000 *$ & 7.234 \\
\hline$[$ France $] *[$ car $]$ & 0.853 & 0.002 & $0.000 *$ & 2.348 \\
\hline$[$ France $] *[$ motorcycle $]$ & 0.593 & 0.001 & $0.000 *$ & 1.809 \\
\hline [France] $*$ [pedal cycle] & 1.054 & 0.002 & $0.000 *$ & 2.868 \\
\hline [France $] *$ [pedestrian] & 1.114 & 0.002 & $0.000 *$ & 3.047 \\
\hline [the Netherlands] * [car] & 0.881 & 0.002 & $0.000 *$ & 2.414 \\
\hline [the Netherlands] $*$ [motorcycle] & 0.412 & 0.001 & $0.000 *$ & 1.510 \\
\hline [the Netherlands] $*$ [pedal cycle] & 0.139 & 0.002 & $0.000 *$ & 1.149 \\
\hline [the Netherlands] $*$ [pedestrian] & 1.499 & 0.002 & $0.000 *$ & 4.476 \\
\hline$[\mathrm{UK}] *[\mathrm{car}]$ & 0.775 & 0.001 & $0.000 *$ & 2.171 \\
\hline$[\mathrm{UK}] *[$ motorcycle $]$ & 0.726 & 0.001 & $0.000 *$ & 2.067 \\
\hline UK] $*$ [pedal cycle] & 0.269 & 0.002 & $0.000 *$ & 1.309 \\
\hline$[\mathrm{UK}] *[$ pedestrian $]$ & 1.343 & 0.002 & $0.000 *$ & 3.829 \\
\hline \multicolumn{5}{|l|}{ [Country]*[Road user type $]^{*}[$ Police severity $]$} \\
\hline [Czech Republic] $*[$ car] $*$ [slight injury $]$ & -0.059 & 0.044 & $0.000 *$ & 0.943 \\
\hline [Czech Republic] $*$ [motorcycle] * [slight injury] & -0.114 & 0.048 & $0.000 *$ & 0.892 \\
\hline [Czech Republic] $*$ [pedal cycle] * [slight injury] & -0.095 & 0.046 & $0.000 *$ & 0.910 \\
\hline [Czech Republic] $*$ [pedestrian] * [slight injury] & 0.148 & 0.047 & $0.000 *$ & 1.160 \\
\hline$[$ France $] *[$ car $] *[$ slight injury $]$ & 0.223 & 0.007 & $0.000 *$ & 1.249 \\
\hline$[$ France $] *[$ motorcycle $] *[$ slight injury $]$ & 0.212 & 0.006 & $0.000 *$ & 1.236 \\
\hline$[$ France $] *[$ pedal cycle $] *[$ slight injury & -0.390 & 0.011 & $0.000 *$ & 0.677 \\
\hline$[$ France $] *[$ pedestrian $] *[$ slight injury $]$ & 0.080 & 0.009 & $0.000 *$ & 1.083 \\
\hline$[$ Netherlands $] *[$ motorcycle $] *$ [slight injury $]$ & 0.050 & 0.005 & $0.000 *$ & 1.051 \\
\hline$[$ Netherlands $] *[$ pedal cycle $] *[$ slight injury & -0.189 & 0.004 & $0.000 *$ & 0.827 \\
\hline$[$ Netherlands $] *$ [pedestrian] $*$ [slight injury & -1.381 & 0.010 & $0.000 *$ & 0.251 \\
\hline$[\mathrm{UK}] *[\mathrm{car}] *[$ slight injury $]$ & -0.159 & 0.007 & $0.000 *$ & 0.853 \\
\hline$[\mathrm{UK}] *[$ motorcycle $] *[$ slight injury & 0.253 & 0.004 & $0.000 *$ & 1.288 \\
\hline$[\mathrm{UK}] *$ [pedal cycle $] *$ [slight injury $]$ & 0.093 & 0.003 & $0.000 *$ & 1.097 \\
\hline$[\mathrm{UK}] *$ [pedestrian] $*$ [slight injury $]$ & -1.139 & 0.010 & $0.000 *$ & 0.320 \\
\hline$[\mathrm{UK}] *$ [pedestrian $] *$ [slight injury $]$ & 0.262 & 0.006 & $0.000 *$ & 1.300 \\
\hline
\end{tabular}

Reference groups: Country: Greece, Road User Type: Other road user, Police severity: Serious injury

* indicates a significant effect

French and Hungarian regions for all user types. It was also found that the increased under-reporting rates in the Greek region correspond to those road user types that the police classified as 'other', possibly revealing a weakness of the police reporting system as per the assignment of road user type.

Finally, an important effect of the degree of mis-reporting injury severity on the overall under-reporting rates was identified for some areas; in particular, increased odds of underreporting in the Czech, French and Hungarian regions, were associated with casualties reported as slight by the police but assigned an MAIS $>2$ by hospitals. These cases correspond to casualties whose injury severity was mis-reported by the police.

These analyses reveal specific particularities of each country/region, indicating areas on which authorities should focus their efforts. The results suggest that all four variables examined are key factors affecting the level of injury underreporting both within and across the examined areas in $\mathrm{Eu}-$ rope. Additional important factors may nevertheless exist, not among those that were currently available for analysis. For instance, the Greek regional study revealed increased injury 
Fig. 2 Relative underreporting rates between countries/regions and road user types

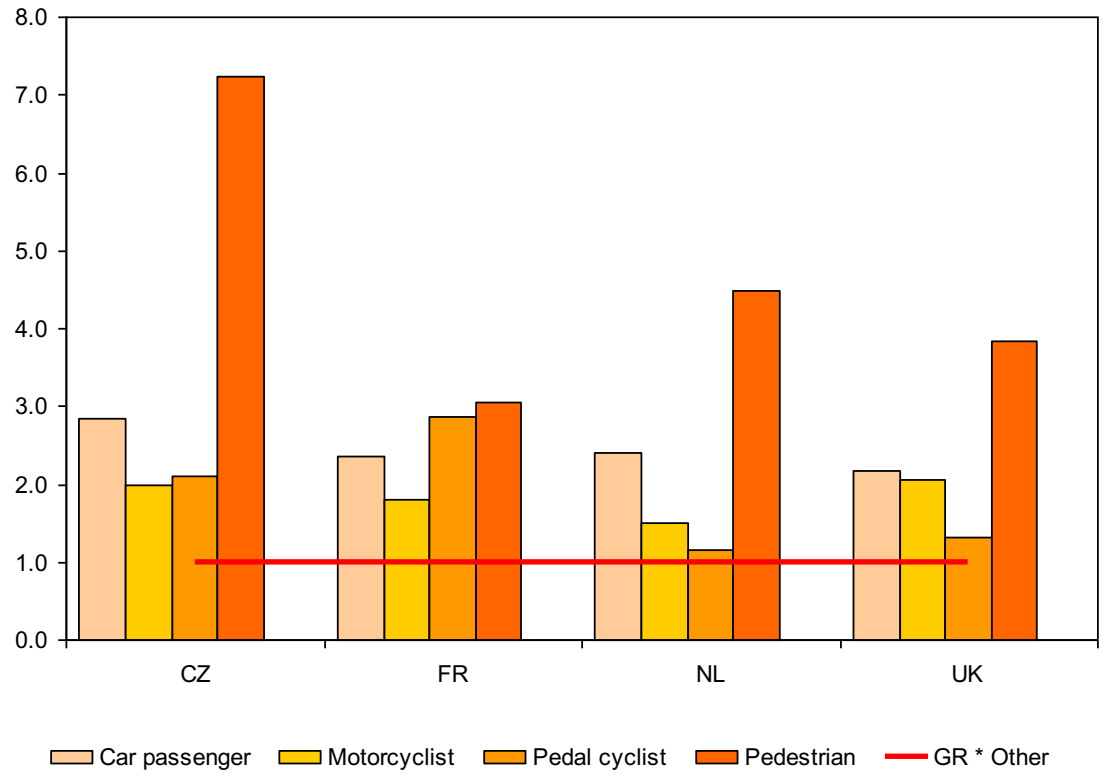

under-reporting for female car driver and passengers, as well as for young individuals of 18-24 years of age [21]. Within the French regional study, under-reporting was also found to vary with road type and area type [1]. Finally, significantly different under-reporting rates per age and gender have been identified in previous national studies in the Netherlands [12]. The analysis of such effects at European level would therefore be a most useful topic for further research.

The modelling results revealed a number of significant effects on under-reporting and also allowed for the quantification of these effects through the calculation of relative ratios. This methodology was very efficient in the particular context of analysis and is considered to be promising for similar analyses on more detailed and extensive results (more countries, larger regions, more harmonized national/regional studies, more disaggregate conversion factors) once these are available.

Certainly, some of these effects may be attributed to specific features of the related national/regional studies and some inevitable methodological compromises. For instance, the studies in Spain and Hungary may not be fully representative of annual patterns (see Table 1). Moreover, given the differences in spatial coverage, part of the identified variations of the under-reporting problem may be due to urban vs. rural reporting patterns (e.g. when comparing Czech Republic results to Hungary results), or to tourist area reporting patterns
Fig. 3 Relative underreporting rates between countries/regions, police severity scores and road user types

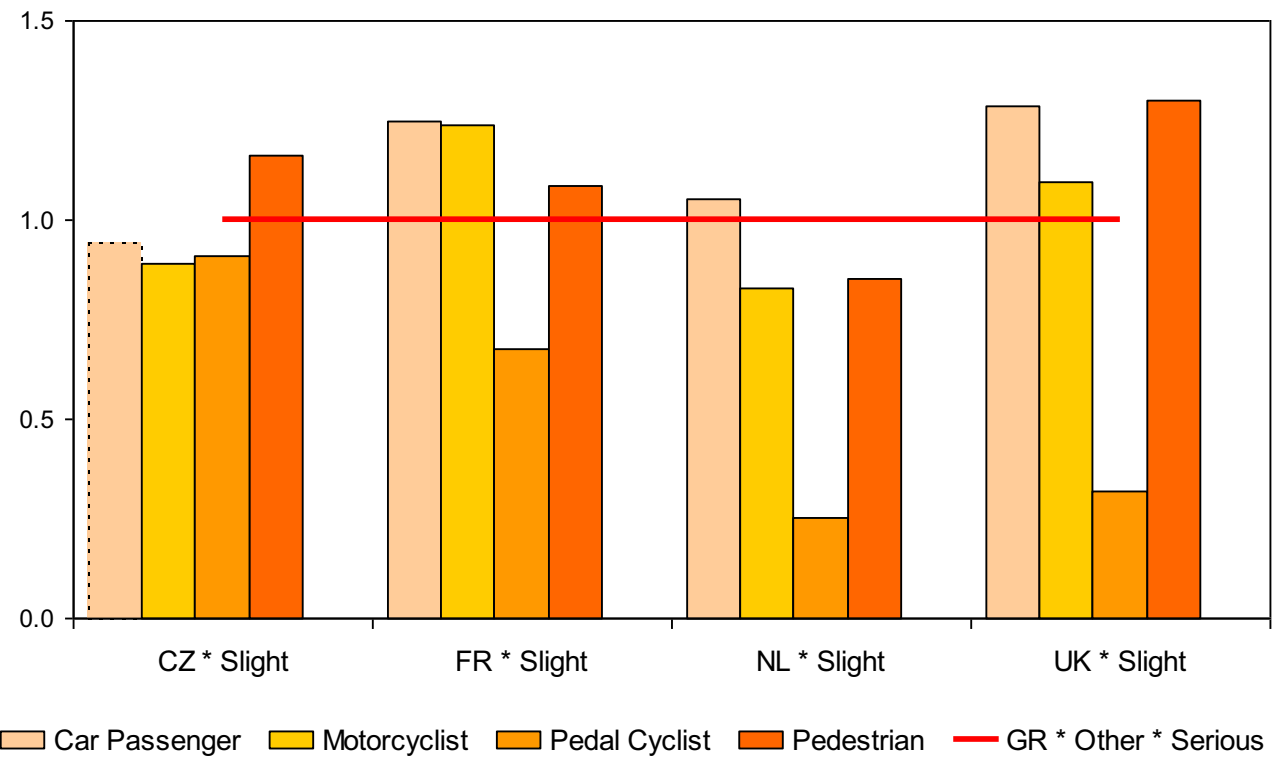


(e.g. when considering the Greek results). Moreover, part of the effects identified may also reflect differences in national definitions of injury severity, and also in the way the police implement these definitions on the accident scene.

It is thus inevitable that that the strength of the results achieved by the various studies somewhat differs, if only on statistical grounds. It is not possible, therefore, to consider these results as fully representative of national patterns. Overall, however, the results achieved are indicative of what could be expected from a large scale, properly resourced European study on under-reporting, and are still considered to be an important step forward in comparing the numbers of road accident casualties across European regions [6].

The results of this research are based on data collected on 2005 , leading to the estimation of the under-reporting coefficients on 2008. Consequently, the results of this research reflect the extent of the under-reporting problem in these countries over that specific period. Moreover, the recording methods of police and hospitals may have been improved nowadays in some countries, being more automated, thus possibly leading to a different picture in terms of underreporting coefficients.

However, the data used in the present study come from ad hoc national studies, which were unique at the time of data collection, due to the particular and largely common methodologies used for data and estimation, and it is thus currently unfeasible to update the results of these national studies with more recent data. In particular, most countries carried out the record linkage as part of the SafetyNet research project, i.e. as a pilot study (i.e. Austria, Hungary, Czech Republic, Greece). The other countries are routinely carrying out police record linkage with hospital data for decades (i.e. Netherlands, France, United Kingdom, City of Barcelona), and it is natural that data linkage methods in these countries have further evolved and have been updated with more recent data.

For instance, Reurings and Bos [22] applied a more sophisticated linkage method for injury under-reporting in the Netherlands, namely a probabilistic distance-based linkage; the method was applied on 1993-2008 data. Moreover, Novoa et al.[19]) applied similar methods with those of the Spanish regional study in a larger area, with more recent data, namely 2000-2007. Ward et al. [27] carried out an in-depth pilot study in the UK, in order to better understand the way Police records injury severity and analyse recent medical data for the development of injury categories that have medical validity but would be practical for a non-specialist police officer to assign. For an exhaustive review of most recent methods for data linkage and under-reporting coefficients estimation, the reader is referred to OECD/ITF [20].

The injury under-reporting problem is a particular aspect of the road safety problem and, although related efforts should start being implemented at national/regional level, it could eventually be tackled at European level. In this context, the knowledge of the extent and the variations of under-reporting in different countries, as well as the variations in the related determinants in different countries, may assist not only in addressing the under-reporting problem globally, but also towards the adoption of a common European definition for injury severity, a need that is underlined in several studies.

Recent research [9] has noted that although the problem of under-reporting is unlikely to be eliminated, it can be substantially reduced. Given that casualty severity can often only be determined a long time after the accident, a definition of serious injury in terms of impairment would be difficult to implement in practice. The problem of under-reporting and misclassification of injuries could probably be addressed by improving injury recording at hospitals and other medical institutions, rather than trying to make the police attend to more traffic accidents than they do. The merging of hospital records and police records may lead to considerable improvement of accident statistics and the problem of under-reporting and misclassification of injury severity.

Acknowledgments Part of this research was co-financed by the European Commission, within the SafetyNet Integrated Project of the 6th Framework Programme.

The authors would like to address special thanks to the SafetyNet Task 1.5 research team, namely Emmanuelle Amoros (INRETS - France), Niels Bos (SWOV - Netherlands), Stefan Hoeglinger (KfV - Austria), Peter Hollo (KTI - Hungary), Catherine Perez (ASPB - Spain) and Jan Tecl (CDV - Czech Republic), for collecting and making available the under-reporting data from the national/regional studies.

The authors would also like to thank the SafetyNet WP7 partners for their valuable feedback and suggestions on previous drafts of the work presented here, as well as Louise Walter (TRL - Crowthorne), for her useful methodological comments on an earlier draft of this work.

Open Access This article is distributed under the terms of the Creative Commons Attribution License which permits any use, distribution, and reproduction in any medium, provided the original author(s) and the source are credited.

\section{References}

1. Amoros E, Martin JL, Laumon B (2006) Under-reporting of road crash casualties in France. Accid Anal Prev 38:627-635

2. Aptel I, Salmi LR, Masson F, Bourde A, Henrion G, Erny P (1999) Road accident statistics: discrepancies between police and hospital data in a French island. Accid Anal Prev 31:101-108

3. Alsop J, Langley J (2001) Under-reporting of motor vehicle traffic crash victims in New Zealand. Accid Anal Prev 33:353-359

4. Brenner H (1994) Application of capture-recapture methods for disease monitoring: potential effects of imperfect record linkage. Methods Inf Med 33(5):502-506

5. Broughton J, Amoros E, Bos N, Evgenikos P, Holló P, Pérez C, Tecl J (2007) Estimating the real number of road accident casualties. Deliverable 1.15 - Final Report on Task 1.5 of the SafetyNet Integrated Project. TRL, Crowthorne. Available on-line at: http:// erso.swov.nl/safetynet/fixed/WP1/D1.15_Estimation_real_number of_road_accident_casualties_final $\% 20$ report_3.pdf 
6. Broughton J, Keigan M, Yannis G, Evgenikos P, Chaziris A, Papadimitriou E, Bos N, Hoeglinger S, Pérez C, Amoros E, Holló $\mathrm{P}$, Tecl J (2010) Estimation of the real number of road casualties in Europe. Saf Sci 48(3):365-371

7. Cryer PC, Westrup S, Cook AC, Ashwell V, Bridger P, Clarke C (2001) Investigation of bias after data linkage of hospital admissions data to police road traffic crash reports. Inj Prev 7:234-241

8. Elvik R, Mysen AB (1999) Incomplete accident reporting: Metaanalysis of studies made in 13 countries. Transp Res Rec 133-140

9. ETSC - European Transport Safety Council (2007). Social and economic consequences of road traffic injury in Europe. Brussels, 2007. Available on-line at: http://www.etsc.eu/documents/Social $\% 20 \mathrm{and} \%$ 20 economic $\% 20$ consequences $\% 20$ of $\% 20$ road $\% 20$ traffic $\%$ 20injury\%20in\%20Europe.pdf

10. Everitt BS (1977) The analysis of contingency tables. Chapman and Hall

11. Goodman LA (1973) Guided and unguided methods for the selection of models for a set of T multidimensional contingency Tables. J Am Stat Assoc 68:165-175

12. Harris $S$ (1990) The real number of road traffic accident casualties in the Netherlands: a year-long survey. Accid Anal Prev 22:371-378

13. Hays WL (1981) Statistics, 3rd edition, Holt-Saunders International Editions

14. IRTAD - International Traffic Safety Data and Analysis Group (2007) Under-reporting of road traffic casualties. IRTAD Special Report, OECD/ITF

15. Kim K, Li L, Richardson J, Nitz L (1998) Drivers at fault: Influences of Age, Sex and Vehicle Type. J Saf Res 29(3):171-179

16. Morris A, Mackay M, Wodzin E, Barnes J (2003) Some injury scaling issues in UK crash research. In Proceedings of the 2003 International IRCOBI Conference on the Biomechanics of Impact, IRCOBI, Lisbon, Portugal 24-26 September, 2003:283-291

17. Morrison A, Stone DH (2000) Capture-recapture: a useful methodological tool for counting traffic related injuries? Inj Prev 6(4): 299-304

18. Nakahara S, Wakai S (2001) Under-reporting of traffic injuries involving children in Japan. Inj Prev 7:242-244
19. Novoa AM, Pérez K, Santamariña-Rubio E. Dirección General de Trafico (2009) Ministerio del Interior. [In Spanish]. www.dgt.es/ was6/portal/contenidos/documentos/seguridad_vial/estudios_ informes/Estimacion_heridos_graves_y_muertos_final.pdf

20. OECD/ITF (2011) Reporting on serious road traffic casualties. Combining and using different data sources to improve understanding of non-fatal road traffic crashes. Paris, 2011. http:// internationaltransportforum.org/irtadpublic/pdf/Road-CasualtiesWeb.pdf

21. Petridou ET, Yannis G, Terzidis A, Dessypris N, Germeni E, Evgenikos P, Tselenti N, Chaziris A, Skalkidis I (2009) Linking emergency medical department and road traffic police casualty data: a tool in assessing the burden of injuries in less resourced countries. Traffic Inj Prev 10(1):37-43

22. Reurings MCB, Bos NM (2009) Seriously injured road crash casualties in the Netherlands in the period 1993-2008; the real number of in-patients with a minimum MAIS of 2 (Dutch Language Only) SWOV report R-2009. www.swov.nl/rapport/R-2009-12.pdf

23. Rosman DL (2001) The Western Australian Road Injury Database (1987-1996): Ten years of linked police, hospital and death records of road crashes and injuries. Accid Anal Prev 33:81-88

24. Sciortino S, Vassar M, Radetsky M, Knudson MM (2005) San Francisco pedestrian injury surveillance: Mapping, under-reporting, and injury severity in police and hospital records. Accid Anal Prev 37:1102-1113

25. Tercero F, Andersson R (2004) Measuring transport injuries in a developing country: an application of the capture-recapture method. Accid Anal Prev 36(1):13-20

26. Ward H, Lyons R, Thoreau R (2006) Road safety research report no. 69 , under-reporting of road casualties - phase 1, Department for Transport (DfT)

27. Ward H, Lyons R, Gabbe B, Thoreau R, Pinder L, Macey S (2010) Review of police road casualty injury severity classification-A feasibility study. Road safety research report no. 119, London: Department for Transport

28. Zaloshnja E, Miller T (2004) Costs of large truck-involved crashes in the United States. Accid Anal Prev 36(5):801-808 